www.nature.com/pj

\title{
Characterization of the microvoids of a tetramethyl polycarbonate/polystyrene blend system using Xe sorption measurements and ${ }^{129}$ Xe NMR spectroscopy
}

\author{
Hiroaki Yoshimizu, Takafumi Murakami, Tomoyuki Suzuki and Yoshiharu Tsujita
}

Relationships among the ${ }^{129}$ Xe NMR chemical shift, Xe sorption properties and density in the miscible tetramethyl bisphenol A polycarbonate (TMPC)/polystyrene (PS) polymer blend system were investigated to estimate the variation of microvoids resulting from blending. The Xe sorption properties of the TMPC/PS blend system indicated that blending reduced the amount of microvoids. The ${ }^{129} \mathrm{Xe}$ NMR chemical shift of the ${ }^{129} \mathrm{Xe}$ in the blend showed a nonlinear low-field shift with an increasing amount of total Xe sorbed for all the sample films. The estimation of microvoids in this polymer blend system using ${ }^{129} \mathrm{Xe}$ NMR spectroscopy has been coincident with the variation in the density and Xe sorption properties.

Polymer Journal (2012) 44, 827-831; doi:10.1038/pj.2012.128; published online 27 June 2012

Keywords: gas sorption properties; microvoid; polymer blend; PS; TMPC; ${ }^{129} \mathrm{Xe}$ NMR

\section{INTRODUCTION}

The microvoids in glassy polymers are part of the interchain microspaces in the frozen segmental motions of the main chains. ${ }^{1-3}$ The microvoids significantly affect the gas permeation, diffusion and sorption properties of glassy polymers. ${ }^{4-6}$ In other words, the gas sorption property of a glassy polymer can provide information about the microvoids. Generally, the gas sorption isotherm of a glassy polymer can be interpreted using the dual-mode sorption model, ${ }^{1-7}$ which is represented by the following equation,

$$
C=C_{\mathrm{D}}+C_{\mathrm{H}}=k_{\mathrm{D}} p+\frac{C_{\mathrm{H}}^{\prime} b p}{1+b p}
$$

where $C$ is the equilibrium sorption amount at pressure $p$. The subscripts D (Dissolved) and $\mathrm{H}$ (Hole) correspond to the Henry and Langmuir sites, respectively. $C_{\mathrm{D}}$ and $C_{\mathrm{H}}$ are concentrations due to Henry's law and the Langmuir mode contributions, respectively. $k_{\mathrm{D}}$ is Henry's law solubility coefficient, $b$ is an affinity constant of the Langmuir site and $C_{\mathrm{H}}{ }^{\prime}$ is the hole saturation constant in the Langmuir sorption mode. The value of $C_{\mathrm{H}}{ }^{\prime}$ corresponds to the unrelaxed volume (so-called 'excess free volume') of a glassy polymer. This volume is defined as a gap between the specific and hypothetical equilibrium super-cooled liquid volumes. The unrelaxed volume increases with the increasing difference between the observation temperature and the glass-transition temperature and is related to the total amount of microvoids. Therefore, one can obtain essential information about the unrelaxed volume and microvoids from the $C_{\mathrm{H}}$ and $C_{\mathrm{H}}{ }^{\prime}$ parameters.
Recently, we demonstrated that ${ }^{129} \mathrm{Xe}$ NMR spectroscopy is a powerful technique for characterizing the higher-ordered structures of polymer solids. ${ }^{8-15}$ As the Xe atom has a very large polarizability, the ${ }^{129} \mathrm{Xe}$ NMR signal is sensitive and easily influenced by its environment; specifically, the induced ${ }^{129} \mathrm{Xe}$ NMR chemical shift is strongly altered by the Xe electron density. The NMR chemical shifts for glassy polymers exhibited a nonlinear low-field shift with an increasing amount of Xe sorption because of the fast exchange of Xe between the Henry and Langmuir sites; therefore, we calculated the NMR chemical shifts for each site using the dual-mode sorption parameters. Consequently, we were able to evaluate the mean size of the microvoids in glassy polymers. ${ }^{9}$ Our reported data for polystyrene (PS), bisphenol A polycarbonate (PC), tetramethyl bisphenol A PC (TMPC) and poly(2,6-dimethyl-1,4-phenylene oxide) (PPO) were similar to data from a related reported technique, positron annihilation lifetime spectroscopy, which suggests that ${ }^{129} \mathrm{Xe}$ NMR spectroscopy is a good method for characterizing microvoids in glassy polymers. Most recently, we have reported the Xe sorption properties and ${ }^{129} \mathrm{Xe}$ NMR spectra of PPO measured at various temperatures. ${ }^{10}$ By analyzing the ${ }^{129} \mathrm{Xe}$ NMR chemical shift, it was observed that the mean diameter of the microvoids in PPO increases linearly with decreasing temperature, and the extrapolated value at the glasstransition temperature was close to $4.4 \AA$, which is the diameter of a $\mathrm{Xe}$ atom. Furthermore, the characteristic cavity in a crystalline region of poly(4-methyl-1-pentene) (PMP) was investigated using gas permeation and ${ }^{129} \mathrm{Xe}$ NMR measurements of PMP membranes with various degrees of crystallinity. ${ }^{11}$ The measured size of the cavity in the PMP crystal was consistent with the results from not only 
crystallographic analysis but also gas permeation and Xe sorption measurements. The size of the molecular cavity in the crystalline syndiotactic PS has also been characterized using ${ }^{129} \mathrm{Xe}$ NMR spectroscopy. ${ }^{12}$ In addition, the density of the side chain regions in a low-density liquid-crystalline polyester with $n$-alkyl side chains has been estimated. ${ }^{13}$ We have also demonstrated that the line width of the ${ }^{129} \mathrm{Xe}$ NMR signal of the ${ }^{129} \mathrm{Xe}$ in this polyester corresponds to its diffusivity.

To establish the microvoid size determination using ${ }^{129} \mathrm{Xe}$ NMR spectroscopy, the accumulation of experimental data is important. Actually, for a miscible polymer blend system, PPO/PS blends, it has been successfully concluded that the contraction of microvoids occurs by blending, based on the Xe sorption properties and the ${ }^{129}$ Xe NMR chemical shift analysis. ${ }^{14,15}$ In this study, a miscible polymer blend system, TMPC/PS blends, was analyzed. The TMPC/ PS blend system is a well-known miscible blend, and many studies on this system have been reported elsewhere. ${ }^{16-20}$ Using these blends, it becomes easy to control the contents of microvoids, as in the case of $\mathrm{PPO} / \mathrm{PS}$ blends. However, because the glass-transition temperature of TMPC is lower than that of PPO, the unrelaxed volume and the total amount of microvoids in the TMPC/PS blends are smaller than those of the PPO/PS blends. If the results obtained are similar to those obtained with PPO/PS blends despite the relatively small size of the microvoids in TMPC/PS blends, this study will be a good indicator of the high reliability of microvoid size determination using ${ }^{129} \mathrm{Xe}$ NMR spectroscopy. Therefore, the relationship between variations of microvoids and Xe sorption properties for TMPC/PS blends were investigated using Xe sorption and ${ }^{129} \mathrm{Xe}$ NMR measurements.

\section{EXPERIMENTAL PROCEDURE}

Sample films (TMPC/PS ratio $=0 / 100,20 / 80,50 / 50,80 / 20$ and 100/0) were prepared using the solution-casting method with chloroform as a co-solvent for TMPC and PS. The film thickness was $\sim 50-100 \mu \mathrm{m}$. Each film was annealed above the glass-transition temperature $\left(T_{\mathrm{g}}\right)$ for $3 \mathrm{~h}$ and then cooled slowly. The film density was determined using the flotation method with a $\mathrm{NaBr}$ aqueous solution at $25^{\circ} \mathrm{C}$.

Xe sorption measurements were performed using a gravimetric sorption apparatus with an electromicrobalance (CAHN 2000, Cahn Instruments, Inc., Cerritos, CA, USA) at $25^{\circ} \mathrm{C}$. After the sorption apparatus containing the film was sufficiently evacuated, the desired pressure of $\mathrm{Xe}$ was introduced into the apparatus. The amount of Xe sorbed into the film was determined after correcting for the buoyancy. The $T_{\mathrm{g}}$ of the sample films were measured using a differential scanning calorimeter (DSC-7, Perkin-Elmer Co., Waltham, MA, USA) at a heating rate of $10^{\circ} \mathrm{C} \mathrm{min}^{-1}$.

The cut and weighed film samples were packed into a $10-\mathrm{mm} \Phi$ Pyrex NMR sample tube with thick walls (type 513-7 JYH-7, Wilmad-LabGlass, Vineland, NJ, USA) and degassed in vacuo for at least $24 \mathrm{~h}$. A desired amount of Xe (with a natural abundance of ${ }^{129} \mathrm{Xe}$ ) was introduced into the NMR tube with the aid of liquid nitrogen, and then the tube was sealed with a Teflon valve. After a sufficient amount of time required to achieve an equilibrium sorption state under isothermal conditions (at $25^{\circ} \mathrm{C}$ ) had elapsed, the NMR experiment was performed. The internal pressure of this sealed NMR tube was determined by subtracting the amount of Xe sorbed into a sample from the total amount of Xe in the tube. The sorption amount at any pressure can be exactly predicted from the sorption isotherm data, and the total amount of $\mathrm{Xe}$ in the tube is easily obtained by weighing. The ${ }^{129}$ Xe NMR spectrum was recorded on an INOVA400 NMR spectrometer (Agilent Technologies, Ltd., Santa Clara, CA, USA) at $110 \mathrm{MHz}$ and $25^{\circ} \mathrm{C}$ using the single pulse method with a $45^{\circ}$ pulse. The repetition time was set to be $10 \mathrm{~s}$, and the accumulation times were from 500 to 3000 to obtain a good signal to noise ratio. All of the ${ }^{129} \mathrm{Xe}$ NMR chemical shifts were referenced to an external standard of gaseous ${ }^{129} \mathrm{Xe}$ at zero pressure.

\section{RESULTS AND DISCUSSION}

The $T_{\mathrm{g}}$ and density values are summarized in Table 1 . In the DSC thermograms from all of the blended sample films, only one heat flow
Table 1 Glass-transition temperature $\left(T_{\mathrm{g}}\right)$ and density of TMPC/PS blend system at $25^{\circ} \mathrm{C}$

\begin{tabular}{lcc}
\hline TMPC/PS & $\mathrm{T}_{g}\left({ }^{\circ}\right)^{\mathrm{a}}$ & Density $\left(\mathrm{gcm}^{-3}\right)^{\mathrm{b}}$ \\
\hline $0 / 100$ & 108 & 1.047 \\
$20 / 80$ & 118 & 1.058 \\
$50 / 50$ & 132 & 1.072 \\
$80 / 20$ & 165 & 1.081 \\
$100 / 0$ & 196 & 1.086 \\
\hline
\end{tabular}

atermined by DSC

${ }^{b}$ Determined by a flotation method with $\mathrm{NaBr}$ aqueous solution.

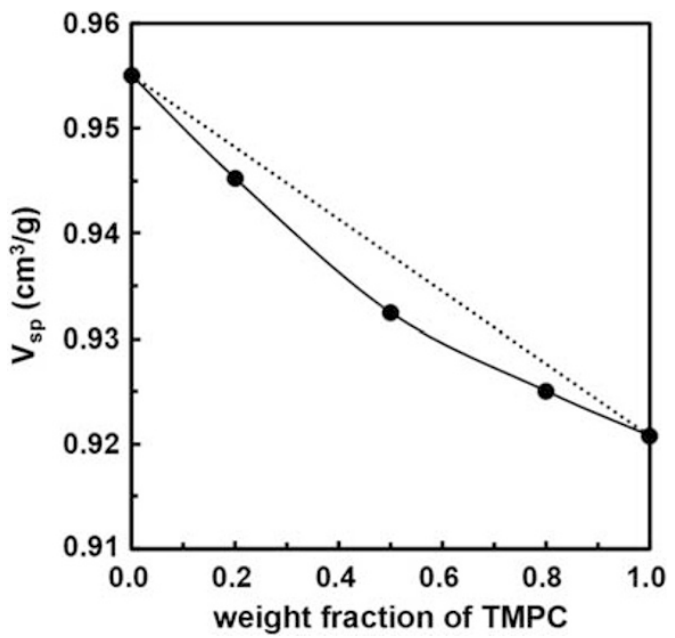

Figure 1 Specific volume $\left(V_{\mathrm{sp}}\right)$ plotted against the weight fraction of TMPC in the TMPC/PS blend system at $25^{\circ} \mathrm{C}$.

jump was observed. Therefore, all of the blended films prepared in this study are miscible, and the observed $T_{\mathrm{g}}$ values were similar compared with those reported in the literature. ${ }^{17}$ It was also confirmed that all of the sample films were in a glassy state at $25^{\circ} \mathrm{C}$. Figure 1 shows the dependence of the specific volume $\left(V_{\mathrm{sp}}\right)$ on the composition of the films, which was determined from the density measurements. The $V_{\mathrm{sp}}$ of the blend is lower than that expected from the simple additive rule of the weight fraction of a pure polymer in a blend and the specific volumes of pure polymers, which is presented as a dotted straight line in Figure 1. Therefore, it can be said that volume contraction results from blending in the TMPC/PS blend system.

The Xe sorption isotherms are presented in Figure 2. It is clear that these isotherms are concaved toward the pressure axis. These isotherms could also be explained using the dual-mode sorption model (see equation (1)), and the results of curve fitting are presented in Figure 2 as solid lines. The dual-sorption parameters were determined using the nonlinear least-squares method, and are summarized in Table 2. The composition dependence of $b$ was not confirmed because the $b$ values of pure polymers are similar to each other. However, the $k_{\mathrm{D}}$ and $C_{\mathrm{H}}{ }^{\prime}$ values appeared to show a systematic variation with the polymer ratio. $C_{\mathrm{H}^{\prime}}$ is a good indicator of microvoids in glassy polymers. Figure 3 shows the plot of $C_{\mathrm{H}}{ }^{\prime}$ against the volume fraction of TMPC in the blend system. It appears that the obtained $C_{\mathrm{H}}{ }^{\prime}$ value is smaller than that expected from the simple additive rule for each blend sample, whereas $k_{\mathrm{D}}$ generally follows the exponential additive rule. This fact indicates that blending has 


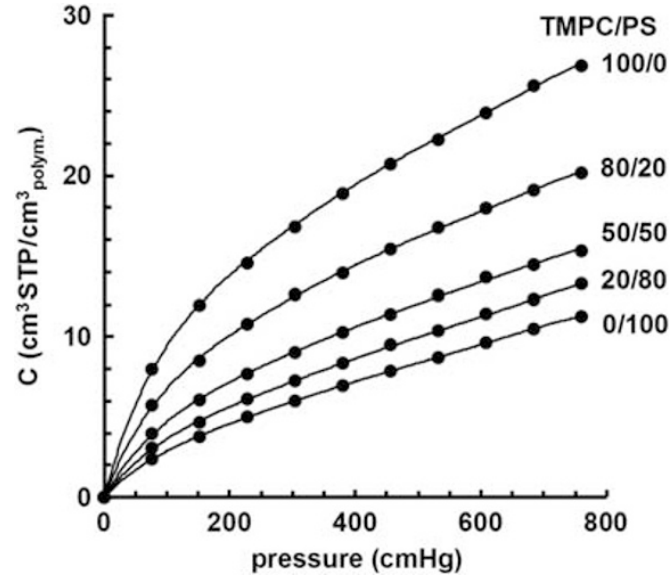

Figure 2 Sorption isotherms of Xe in the TMPC/PS blend system at $25^{\circ} \mathrm{C}$.

Table 2 Dual-mode sorption parameters of Xe of TMPC/PS blend system at $25^{\circ} \mathrm{C}$

\begin{tabular}{|c|c|c|c|}
\hline TMPC/PS & $\begin{array}{c}\mathrm{k}_{D} \times 10^{2} \\
\left(\mathrm{~cm}^{3}(\mathrm{STP}) \mathrm{cm}^{-3} \text { polym. } \mathrm{cm} \mathrm{Hg}^{-1}\right)\end{array}$ & $\begin{array}{c}\mathrm{C}_{\mathrm{H}^{\prime}} \\
\left(\mathrm{cm}^{3}(\mathrm{STP}) \mathrm{cm}^{-3}{ }_{\text {polym. }}\right)\end{array}$ & $\begin{array}{c}\mathrm{b} \times 10^{3} \\
(\mathrm{~cm} \mathrm{Hg}-1)\end{array}$ \\
\hline $0 / 100$ & 1.04 & 3.93 & 8.83 \\
\hline $20 / 80$ & 1.16 & 5.04 & 9.57 \\
\hline $50 / 50$ & 1.14 & 7.87 & 8.23 \\
\hline $80 / 20$ & 1.31 & 11.88 & 8.40 \\
\hline $100 / 0$ & 1.71 & 15.99 & 9.25 \\
\hline
\end{tabular}

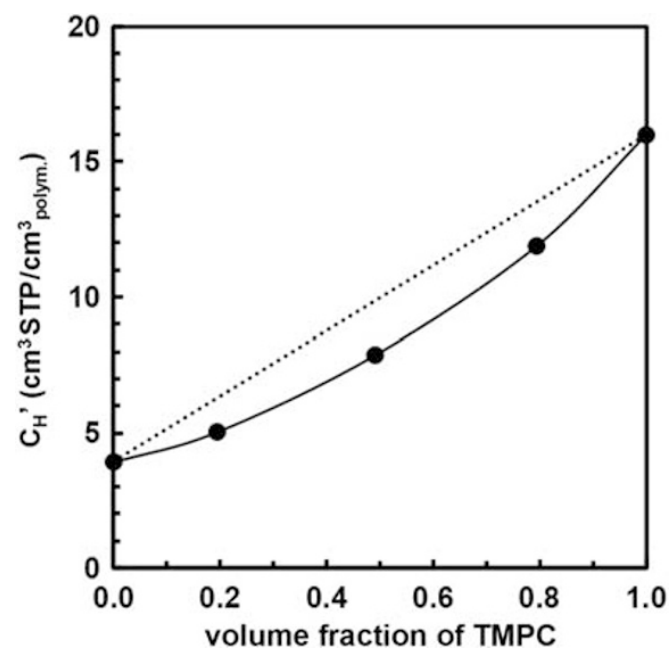

Figure 3 Langmuir saturation constant $\left(C_{H^{\prime}}\right)$ of $\mathrm{Xe}$ plotted against the volume fraction of TMPC in the TMPC/PS blend system at $25^{\circ} \mathrm{C}$.

induced a reduction in the amount of microvoids in the TMPC/PS blend system, whereas the solubility behavior was not remarkably changed by blending. These findings are consistent with the density measurement results.

As an example, Figure 4 shows the ${ }^{129} \mathrm{Xe}$ NMR spectra of ${ }^{129} \mathrm{Xe}$ in a TMPC/PS $(=80 / 20)$ blend film under various pressures of Xe at $25^{\circ} \mathrm{C}$. It is obvious that the NMR peak shifts to lower magnetic fields with increasing pressures of $\mathrm{Xe}$, and the peak shape is almost

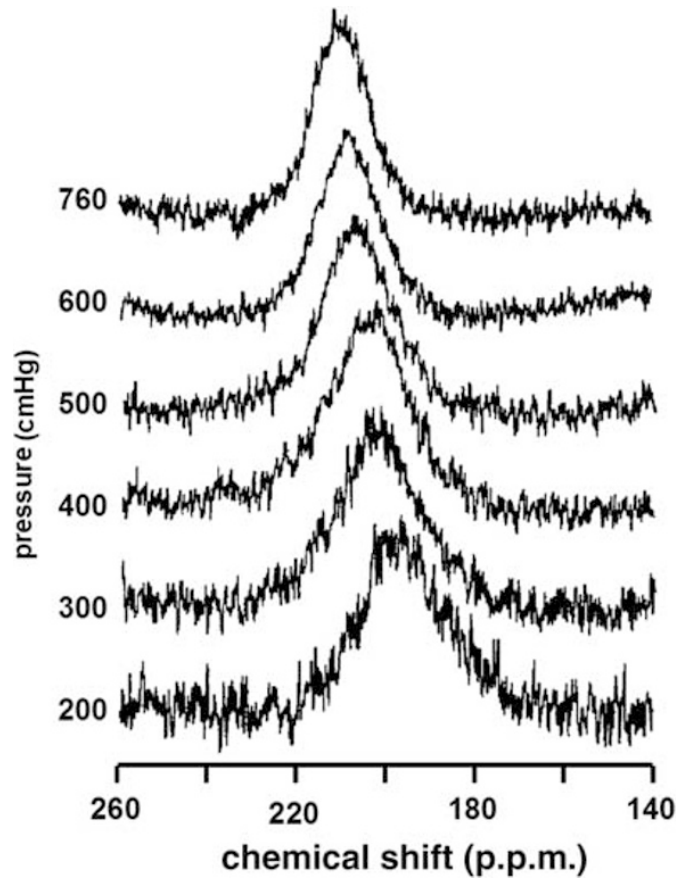

Figure $4{ }^{129} \mathrm{Xe}$ NMR spectra of the ${ }^{129} \mathrm{Xe}$ in a TMPC/PS $(=80 / 20)$ blend film under various pressures of $\mathrm{Xe}$ at $25^{\circ} \mathrm{C}$.

symmetric. Similar results were obtained for other samples. These downfield shifts are caused by increasing interactions among the Xe atoms. $^{21,22}$ Additionally, these symmetric peaks indicate that $\mathrm{Xe}$ atoms, which are dissolved in the samples, diffuse fast and then rapidly exchange between the Henry and Langmuir sorption sites on the NMR time scale.

Jameson et al. ${ }^{23}$ reported that the ${ }^{129} \mathrm{Xe}$ NMR chemical shift of gaseous pure Xe linearly shifts to low field with increasing densities in amagat units ( 1 amagat is the density of a gas under STP conditions) in the low pressure region until $\sim 100$ amagat. Furthermore, Fraissard and collegues ${ }^{21,22}$ reported that the chemical shifts of ${ }^{129} \mathrm{Xe}$ in zeolites without strong charges also shift linearly with increasing amounts of $\mathrm{Xe}$ sorbed in them. The pressure dependence of the ${ }^{129} \mathrm{Xe}$ NMR chemical shift can be interpreted by the interactions between Xe atoms. The influence of this interaction is basically expressed by the time-averaged distance between them, and this distance can be replaced by frequencies of collisions among them. As a result, the chemical shift shows a linear relationship with the density of Xe, because the probability of three or more body collisions at considerably high densities is ignored. However, the observed ${ }^{129} \mathrm{Xe}$ NMR chemical shifts of all of the sample films prepared in this study exhibit a nonlinear low-field shift with increasing Xe density, that is, the total sorption amount, $C$. As the total sorption amount $(C)$ for glassy polymers is composed of $C_{\mathrm{D}}$ and $C_{\mathrm{H}}$ (see equation (1)), it is necessary to individually evaluate the dependencies of $C_{\mathrm{D}}$ and $C_{\mathrm{H}}$ on the NMR chemical shift of ${ }^{129} \mathrm{Xe}$. Assuming that there is a fast exchange of Xe atoms between the Henry and Langmuir sites, the observed NMR chemical shift $\left(\delta_{\text {obs }}\right)$ appears as a single peak at the resonant position described by

$$
\delta_{\text {obs }}=\phi_{\mathrm{D}} \delta_{\mathrm{D}}+\phi_{\mathrm{H}} \delta_{\mathrm{H}}
$$

where $\phi_{\mathrm{D}}$ and $\phi_{\mathrm{H}}$ are the fractional concentrations of Xe for the Henry and Langmuir sites and $\delta_{\mathrm{D}}$ and $\delta_{\mathrm{H}}$ are the NMR chemical 
shifts for the Henry and Langmuir sites, respectively. The definitions of $\phi_{\mathrm{D}}$ and $\phi_{\mathrm{H}}$ are:

$$
\phi_{\mathrm{D}}+\phi_{\mathrm{H}}=\frac{C_{\mathrm{D}}}{C}+\frac{C_{\mathrm{H}}}{C}=1
$$

These parameters are functions of pressure and can be calculated using the dual-mode sorption parameters (Table 2); therefore, $\phi_{\mathrm{H}}$ is larger than $\phi_{\mathrm{D}}$ in the low pressure region, whereas the opposite relationship is observed in the high pressure region. Under the assumption of a linear low-field shift of Xe sorption amount, $\delta_{\mathrm{D}}$ and $\delta_{\mathrm{H}}$ are individually defined by the following equations,

$$
\begin{aligned}
& \delta_{\mathrm{D}}=\delta(\mathrm{Xe})_{\mathrm{D}}+\delta(\mathrm{S})_{\mathrm{D}}=A_{\mathrm{D}} C_{\mathrm{D}}+\delta(\mathrm{S})_{\mathrm{D}} \\
& \delta_{\mathrm{H}}=\delta(\mathrm{Xe})_{\mathrm{H}}+\delta(\mathrm{S})_{\mathrm{H}}=A_{\mathrm{H}} C_{\mathrm{H}}+\delta(\mathrm{S})_{\mathrm{H}}
\end{aligned}
$$

where $\delta(\mathrm{Xe})_{\mathrm{i}}$ and $\delta(\mathrm{S})_{\mathrm{i}}$ are the NMR chemical shifts due to the interactions between the $\mathrm{Xe}$ atom and the inner wall of the pore, namely, the polymer sample, and between Xe atoms, $A_{\mathrm{i}}$ is a constant proportional to the concentration of Xe and $C_{\mathrm{i}}$ is the amount of Xe sorbed in site i. Using equations (2)-(5), a set of $\delta_{\text {obs }}$ values at observed pressures were reproduced by substituting suitable values for four unknown parameters, $A_{\mathrm{D}}, \delta(\mathrm{S})_{\mathrm{D}}, A_{\mathrm{H}}$ and $\delta(\mathrm{S})_{\mathrm{H}}$. These four parameters were determined when the sum of squares of deviation from the experimental data, $\Sigma\left[\left(\delta_{\text {obs }}{ }^{\text {calc }}-\delta_{\text {obs }}{ }^{\exp }\right)^{2}\right]$, reaches a minimum in the variation steps considered by experimental error, which is defined as a digital resolution of $\sim 0.1$ p.p.m. As an example, the results from the pure PS film are plotted against pressure in Figure 5. The relationships between $\delta_{\mathrm{D}}-p$ and $\delta_{\mathrm{H}}-p$ are linear and concave, respectively, which is in agreement with the results of the pressure dependences of $C_{\mathrm{D}}$ and $C_{\mathrm{H}}$. However, the calculated values of the observed chemical shift, $\delta_{\text {obs }}{ }^{\text {calc }}$, exhibit good agreement with the corresponding experimental data, $\delta_{\mathrm{obs}}{ }^{\exp }$. From these results, the NMR chemical shift of ${ }^{129} \mathrm{Xe}$ sorbed in a glassy polymer apparently exhibits a nonlinear low-field shift with respect to the total sorption amount, $C$. Similar results were obtained for the other samples. The parameters in equations (4) and (5) are summarized in Table 3. This result proves that $A_{\mathrm{H}}$ is larger than $A_{\mathrm{D}}$. This finding indicates that the dependence of the NMR chemical shift of ${ }^{129} \mathrm{Xe}$ on the Xe density in the Langmuir site is larger than that in the Henry site. In practice, for rubbery polymers that contain 'only' Henry sites, the NMR chemical shift of sorbed ${ }^{129} \mathrm{Xe}$ rarely presents a dependency on the Xe density (data not shown), which indicates the relatively large inhibition of the interaction between Xe atoms by the mobile polymer chains. In a similar manner, for a glassy polymer, it can be considered that the local molecular motions of the main chain and/or side chains may provide the Henry-mode sorption site and inhibit the $\mathrm{Xe}-\mathrm{Xe}$ interaction. As there are no inhibitory factors in the Langmuirmode sorption site, that is, microvoids, $A_{\mathrm{H}}$ becomes larger than $A_{\mathrm{D}}$. In other words, the contribution of the Xe-polymer interaction (which is the frequencies of collision between Xe and polymer) to the ${ }^{129} \mathrm{Xe}$ NMR chemical shift at the Henry site is relatively larger than that at the Langmuir site. Therefore, the $\delta(\mathrm{S})_{\mathrm{D}}$ values become larger than those of $\delta(\mathrm{S})_{\mathrm{H}}$, and the polymer composition dependence of $\delta(\mathrm{S})_{\mathrm{D}}$ is lower than that of $\delta(\mathrm{S})_{\mathrm{H}}$.

It can be said that the NMR chemical shift extrapolated to $C_{\mathrm{H}}=0$ for the Langmuir site, that is, $\delta(\mathrm{S})_{\mathrm{H}}$, reflects the mean size of the hole correlated with the microvoids in the glassy polymer. According to Fraissard and collegues ${ }^{21,22}$, when the NMR chemical shift of ${ }^{129} \mathrm{Xe}$ in a micropore of dense materials, such as zeolites, is determined only by the interaction with the walls, the mean free path $(\lambda)$ is linked to this chemical shift, $\delta(S)$. Therefore, $\delta(S)$ can be estimated by the mean size

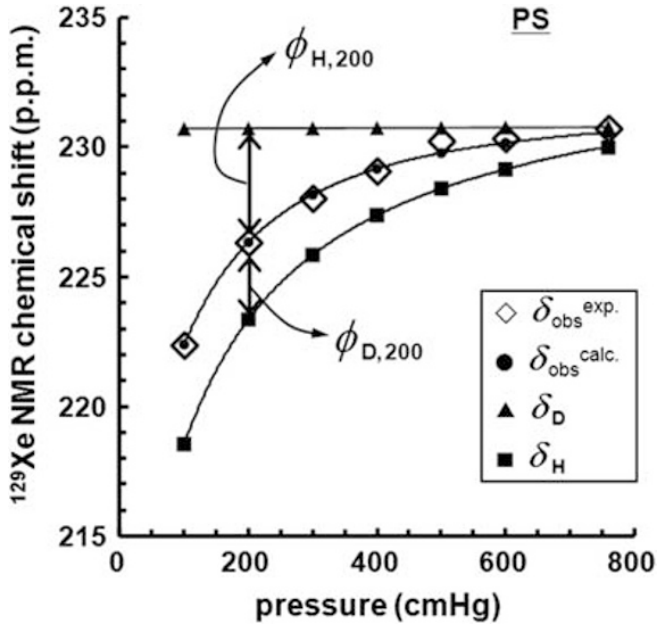

Figure $5{ }^{129} \mathrm{Xe}$ NMR chemical shifts of the ${ }^{129} \mathrm{Xe}$ in a PS film plotted against the pressure of $\mathrm{Xe}$ at $25^{\circ} \mathrm{C}$.

\begin{tabular}{|c|c|c|c|c|c|}
\hline \multirow[b]{2}{*}{ TMPC/PS } & \multicolumn{2}{|c|}{ Henry site } & \multicolumn{2}{|c|}{ Langmuir site } & \multirow[b]{2}{*}{$\begin{array}{l}\mathrm{d}_{s} \\
(\stackrel{\circ}{)})\end{array}$} \\
\hline & $\begin{array}{c}\mathrm{A}_{D} \\
\text { (p.p.m. } \mathrm{cm}_{\text {polym. }}^{3} \\
\left.\mathrm{~cm} \mathrm{~m}^{-3}(S T P)\right)\end{array}$ & $\begin{array}{c}\delta(S)_{D} \\
\text { (p.p.m.) }\end{array}$ & $\begin{array}{c}\mathrm{A}_{H} \\
\text { (p.p.m. } \mathrm{cm}_{\text {polym }}^{3} . \\
\mathrm{cm}^{-3}(\text { STP)) }\end{array}$ & $\begin{array}{c}\delta(S)_{H} \\
\text { (p.p.m.) }\end{array}$ & \\
\hline $0 / 100$ & 0.01 & 233.5 & 5.5 & 206.2 & 5.13 \\
\hline $20 / 80$ & 0.15 & 231.6 & 3.5 & 201.1 & 5.25 \\
\hline $50 / 50$ & 0.16 & 224.6 & 2.6 & 192.1 & 5.48 \\
\hline $80 / 20$ & 0.53 & 222.2 & 2.0 & 178.4 & 5.88 \\
\hline $100 / 0$ & 0.54 & 217.5 & 1.5 & 169.2 & 6.18 \\
\hline
\end{tabular}

Table 3 Parameters of ${ }^{129}$ Xe NMR chemical shifts and $d_{\mathrm{s}}$ of TMPC/ PS blend system at $25^{\circ} \mathrm{C}$

of the hole using the following relationship,

$$
\delta(\mathrm{S})=243 \times \frac{2.054}{2.054+\lambda}
$$

where $\lambda$ is a function of both the shape and dimension of the hole. $\delta(\mathrm{S})$ can be experimentally obtained by linear extrapolating to the zero pressure of Xe using the pressure dependence data of chemical shifts. In the case of glassy polymers, the mean size of the microvoids can be estimated by $\delta(\mathrm{S})_{\mathrm{H}}$ rather than $\delta(\mathrm{S})$. The individual shape of the microvoids is not a complete sphere, but the both shapes and directions of the microvoids are random even if the shape is anisotropic, such as an ellipsoidal hole. In addition, Xe atoms experience many microvoids for NMR observation because of their state in diffusion. Therefore, the statistically averaged shape of the considerable number of microvoids from viewpoints of both of space and time can be regarded as a sphere. When the shape of the hole is spherical, $\lambda$ is derived by

$$
\lambda=\frac{\left(d_{\mathrm{s}}-d_{\mathrm{Xe}}\right)}{2}
$$

where $d_{\mathrm{s}}$ is the diameter of the sphere and $d_{\mathrm{Xe}}$ is the van der Waals diameter of the Xe atom $(4.4 \AA)$. The calculated values of $d_{\mathrm{s}}$ are listed in Table 3. The order of the $d_{\mathrm{s}}$ value is consistent with those of $T_{\mathrm{g}}$ and $C_{\mathrm{H}}{ }^{\prime}$ (see Tables 1 and 2). Here, the mean volume of individual microvoids, $v\left(\mathrm{~cm}^{3}\right)$, is calculated from $d_{s}$. Figure 6 shows the plot of $v$ against the volume fraction of TMPC in the blend system. The $v$ 


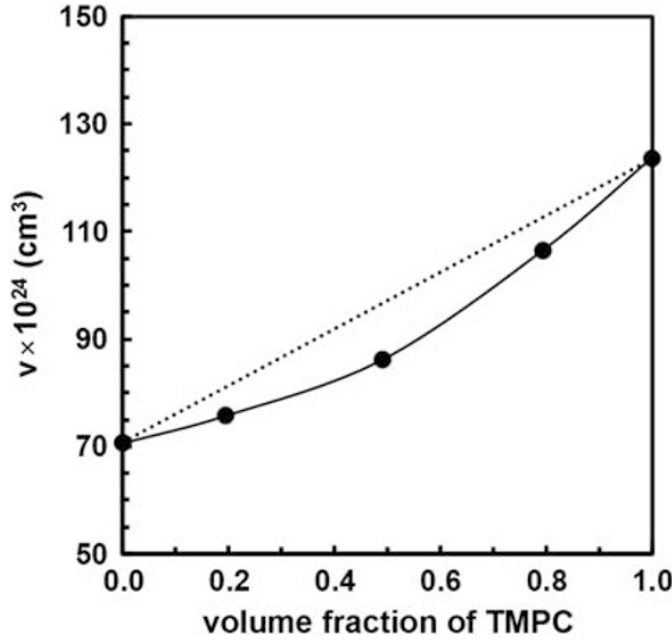

Figure 6 The mean volume of individual microvoids $(v)$ plotted against the volume fraction of TMPC in the TMPC/PS blend system at $25^{\circ} \mathrm{C}$.

values for the blends are smaller than those predicted by a simple additive rule, which is also the case for the $C_{\mathrm{H}}{ }^{\prime}$ values (see Figure 3 ). This finding indicates that there is a decrease in the total amount of microvoids; in other words, $C_{\mathrm{H}}{ }^{\prime}$ is attributed to contraction of the volume of individual microvoids.

\section{CONCLUSIONS}

In this study, relationships between variations of microvoids and gas sorption properties for a miscible TMPC/PS blend system were investigated using Xe sorption and ${ }^{129} \mathrm{Xe}$ NMR measurements. The $C_{\mathrm{H}}{ }^{\prime}$ values for the blends were smaller than those expected from a simple additive rule because of the decrease in the total amount of microvoids resulting from blending. The ${ }^{129} \mathrm{Xe}$ NMR spectra of ${ }^{129} \mathrm{Xe}$ in the blends obtained at various pressures exhibited a nonlinear lowfield shift because of a fast exchange of Xe between the Henry and Langmuir sites. This behavior is one of the characteristic features of glassy polymers compared to many cases of rubbery polymers and zeolites. From the analysis of $\delta(\mathrm{S})_{\mathrm{H}}$, which is the NMR chemical shift that reflects the mean size of the microvoids, it was demonstrated that the mean volume of the individual microvoids varied nonlinearly from $71 \AA^{3}$ for PS to $124 \AA^{3}$ for TMPC with respect to the volume fraction of TMPC in the blend, which indicates a blending-induced contraction of the microvoids. For TMPC/PS blends, it is concluded that the contraction of microvoids occurs by blending and affects the gas sorption properties.

\section{ACKNOWLEDGEMENTS}

We gratefully acknowledge partial financial support by a Grant-in-Aid for Scientific Research (C), No. 20550186 (2008), from the Japan Society for the Promotion of Science.
1 Chan, A. H. \& Paul, D. R. Influence of history on the gas sorption, thermal, and mechanical properties of glassy polycarbonate. J. Appl. Polym. Sci. 24, 1539-1550 (1979).

2 Tsujita, Y., Hachisuka, H., Imai, T., Takizawa, A. \& Kinoshita, T. Solubility and permeability of quenched poly(2,6-dimethyl phenyleneoxide) with various microvoids. J. Membr. Sci. 60, 103-111 (1991).

3 Koros, W. J. \& Paul, D. R. Transient and steady-state permeation in poly(ethylene terephthlate) above and below the glass transition. J. Polym. Sci. Polym. Phys. Ed. 16, 2171-2187 (1978).

4 Hachisuka, H., Tsujita, Y., Takizawa, A. \& Kinoshita, T. $\mathrm{CO}_{2}$ sorption properties and enthalpy relaxation in alternating copoly(vinylidene cyanide-vinyl acetate)s. Polymer 29, 2050-2055 (1988).

5 Hachisuka, H., Tsujita, Y., Takizawa, A. \& Kinoshita, T. Influence of pressure conditioning on the gas transport properties of imidized polyamic acid films. Polymer J. 21, 1019-1025 (1989).

6 Nagai, K., Toy, L. G., Freeman, B. D., Teraguchi, M., Masuda, T. \& Pinnau, I. Gas permeability and hydrocarbon solubility of poly[1-phenyl-2-[p-(triisopropylsilyl)phenyI]acetylene]. J. Polym. Sci. B: Polym. Phys. 38, 1474-1484 (2000).

7 Nakagawa, T., Watanabe, T., Mori, M. \& Nagai, K. In: Freeman, B. D. \& Pinnau, I. (eds Polymer Membranes for Gas and Vapor Separation ACS Symposium Series No. 733 (American Chemical Society, Washington, DC, pp 68-84, 1999).

8 Suzuki, T., Miyauchi, M., Takekawa, M., Yoshimizu, H., Tsujita, Y. \& Kinoshita, T. Characterization of the microvoids in poly (2,6-dimethyl-1,4-phenylene oxide) by means of ${ }^{129}$ Xe NMR spectroscopy. Macromolecules 34, 3805-3807 (2001).

9 Suzuki, T., Miyauchi, M., Yoshimizu, H. \& Tsujita, Y. Characterization of microvoids in glassy polymers by means of ${ }^{129}$ Xe NMR spectroscopy. Polymer J. 33, 934-938 (2001).

10 Yoshimizu, H., Ohta, S., Asano, T., Suzuki, T. \& Tsujita, Y. Temperature dependence of the mean size of microvoids of polyphenyleneoxide studied by analyses of Xe sorption and ${ }^{129}$ Xe NMR chemical shift. Polymer J. 44 (2012).

11 Suzuki, T., Tanaka, T., Nakajima, M., Yoshimizu, H. \& Tsujita, Y. Characterization of the cavity in poly(4-methyl-1-pentene) crystal by gas permeation and ${ }^{129} \mathrm{Xe} N M R$ measurements. Polymer J. 34, 891-896 (2002).

12 Sivakumar, M., Suzuki, T., Yamamoto, Y., Mahesh, K. P. O., Yoshimizu, H. \& Tsujita, Y Structure and properties of the mesophase of syndiotactic polystyrene membrane-vii. Isothermal sorption behavior of xenon. J. Membr. Sci. 238, 75-81 (2004).

13 Yoshimizu, H., Tsukahara, M., Suzuki, T., Toida, J., Ando, A., Watanabe, J. \& Tsujita, Y. Layered structure and Xe sorption and diffusion properties of low-density liquidcrystalline polyester with n-alkyl side chains. J. Mol. Struct. 739, 19-26 (2005).

14 Suzuki, T., Yoshimizu, H. \& Tsujita, Y. Characterization of microvoids in PPO/PS polymer blend by means of ${ }^{129}$ Xe NMR spectroscopy. Desalination 148, 359-361 (2002).

15 Suzuki, T., Yoshimizu, H. \& Tsujita, Y. Analysis of gas transport properties of PPO/PS blends by ${ }^{129}$ Xe NMR spectroscopy. Polymer 44, 2975-2982 (2003).

16 Yang, H., Kwei, T. K. \& Dai, Y. Solid-state NMR study on the miscibility of polystyrene and tetramethyl-bisphenol A polycarbonate blends. Macromolecules 26, 842-843 (1993).

17 Mansour, A. A., Madbouly, S. A., Höhne, G. \& Dollhopf, W. Effect of method of preparation on molecular packing of TMPC/PS blends. Polym. Int. 42, 143-148 (1997).

18 Yagihara, S., Yamada, M., Asano, M., Kanai, Y., Shinyashiki, N., Mashimo, S. \& Ngai, K. L. Dielectric study on $\beta$-relaxation process of tetramethyl-bisphenol-A polycarbonate. J. Non-Cryst. Solids 235-237, 412-415 (1998).

19 Merfeld, G. D. \& Paul, D. R. Light scattering characterization of tetramethyl polycarbonate blends with polystyrene and with styrene-pentabromobenzyl acrylate copolymers. Polymer 41, 649-661 (2000).

20 Cabral, J. T. \& Higgins, J. S. Small angle neutron scattering from the highly interacting polymer mixture TMPC/PSd: no evidence of spatially dependent $\chi$ parameter. Macromolecules 42, 9528-9536 (2009).

21 Demarquay, J. \& Fraissard, J. ${ }^{129}$ Xe NMR of xenon adsorbed on zeolites. Relationship between the chemical shift and the void space. Chem. Phys. Lett. 136, 314-318 (1987).

22 Fraissard, J. \& Ito, T. ${ }^{129}$ Xe N.M.R. study of adsorbed xenon: a new method for studying zeolites and metal-zeolites. Zeolites 8, 350-361 (1988).

23 Jameson, A. K., Jameson, C. J. \& Gutowsky, H. S. Density dependence of ${ }^{129} \mathrm{Xe}$ chemical shifts in mixtures of xenon and other gases. J. Chem. Phys. 53, 2310-2321 (1970). 